\title{
SEROPREVALENCIA DE ANTICUERPOS BACTERICIDAS FRENTE AL MENINGOCOCO C EN CANTABRIA 10 MESES DESPUÉS DE LA CAMPAÑA DE VACUNACIÓN $\left(^{*}\right)$
}

\author{
Álvaro González de Aledo Linos y Jesús García Merino. \\ Consejería de Sanidad, Consumo y Bicnestar Social del Gobierno de Cantabria. \\ (*) Trabajo financiado parcialmente por el Laboratorio SB mediante un acuerdo tripartito con la Consejería de Sa- \\ nidad, Consumo y Bienestar Social de Cantabria y el Instituto de Salud Carlos III.
}

\section{RESUMEN}

Fundamento: En febrero-marzo de 1997 se realizó en Cantabria (Comunidad Autónoma del Estado Español con 541.885 habitantes, de los cuales 107.787 tienen una edad entre 18 meses y 19 años) una campaña de vacunación antimeningocócica dirigida a niños entre 18 meses y 19 años, que abarcó a todos sus municipios y alcanzó una cobertura mayor del $95 \%$. En los 12 meses posteriores la eficacia vacunal fue del $95.68 \%$ en todas las edades. Para ayudar a decidir una revacunación se realizó un estudio de seroprevalencia de anticuerpos bactericidas en la población vacunada.

Métodos: en diciembre de 1997 se analizaron muestras de sangre de 414 niños vacunados, obtenidas al azar de extracciones oportunistas realizadas en Atención Primaria y en Hospitales Públicos de la Comunidad, y de niños escolarizados en las guarderías públicas dependientes de la Dirección General de Bienestar Social de Cantabria. Se analizó la tasa de anticuerpos bactericidas en el Centro Nacional de Microbiología, estableciéndose el nivel de «efecto vacunal» en la dilución 1/8.

Resultados: se obtuvieron los siguientes porcentajes de títulos $\geq 1 / 8$ (entre paréntesis, grupos de edad al vacunarse): $0 \%$ (18-24 meses), $4 \%$ (1.5 a 4 años), $7.1 \%$ ( 1.5 a 6 años), $51.3 \%$ (6 a 12 años) y $81.2 \%$ (12 a 19 años). Debido a que la definición de "efecto vacunal» se cifró en la dilución 1/8 de forma artificial, y a que otros trabajos la cifran en $1 / 4$, en 287 sueros con resultado $<1 / 8$ se repitió el ensayo bactericida con la dilución $1 / 4$, resultando que 286 (el 99.6\%) también dieron negativo. Es decir, que el resultado final no variaría si situásemos el punto de corte en la dilución $1 / 4$ en vez de en $1 / 8$. No se encontraron diferencias significativas según la procedencia de municipios donde hubiera habido casos de meningitis $\mathrm{C}$ o no los hubiera habido.

Conclusiones: la actividad bactericida es muy baja en los menores de 4-6 años, inferior a lo publicado, y mayor por encima de esa edad. Esto contrasta con el excelente resultado clínico-epidemiológico, pues no se ha producido ningún caso entre la población serológicamente más «desprotegida» a pesar de que el meningococo $\mathrm{C}$ ha seguido circulando en Cantabria entre la población que no fue objeto de la campaña.

Palabras clave: Meningococo C. Vacuna meningocócica polisacárido $\mathrm{A}+\mathrm{C}$. Anticuerpos séricos. Respuesta inmune.

Correspondencia:

Alvaro González de Aledo Linos

Dirección General de Sanidad y Consumo

C/ Marqués de la Herida 8

39009 Santander, Cantabria.

Tfno: $207716 / 207691$

Fax: 207706

\section{ABSTRACT \\ Seroprevalence of Bactericidal Antimeningococcal Antibodies in Cantabria (Spain) 10 months after Vaccination Campaign.}

Background: The Self Governing Region of Cantabria within the state of Spain has a population of 541,885 , of which 107,787 individuals are aged from 18 months to 19 years. A vaccination campaign against meningitis was conducted in this Region in February and March, 1997. It was directed at children from the age of 18 months up to 19 years old, and included all municipal areas, achieving a coverage of more than $95 \%$. In the following 12 months the efficacy achieved by the vaccination was $95.68 \%$ for all age groups. To help decide on the need for re-vaccination, a study of the prevalence in serum of bactericide antibodies in the vaccinated population was carried out.

Methods: in December 1997 blood samples from 414 vaccinated children were analysed, obtained at random in opportunist sampling in First - Aid Centres and Public Hospitals within this Region, as well as from children in public kindergartens run by the General Board of Social Well-Being in Cantabria. The number of bactericide antibodies was analysed in the National Centre for Microbiology, and the level of «vaccination effect» was set at a dilution of $1 / 8$.

Results: the following percentages of titres $\geq 1 / 8$ were obtained (the age groups of school pupils are shown in brackets): $0 \%$ (18-24 months old), $4 \%$ (1.5-4 years old), $7.1 \%$ (1.5 to 6 years old), $51.3 \%$ ( 6 to 12 years old). Due to the fact that the definition of the «vaccine effect» was artificially set at a dilution of $1 / 8$. while other studies set it at a dilution of $1 / 4$. in 287 serum samples with a result of $<1 / 8$ the bactericide assay was repeated with a dilution of $1 / 4$, with the result that $286(99.6 \%)$ were negative. I.e., the final result does not vary if we set the cut off point at $1 / 4$ instead of $1 / 8$. No significant differences were found duc to whether or not the samples came from children in municipalities where there had been cases of meningitis $C$.

Conclusions: bactericide activity is very low in those children aged less than 4 - 6 years old, and is less than has been published, although it is greater above this age. This contrasts with the excellent clinical - epidemiological results, as there was no case amongst the least serologically "protected» population, in spite of the fact that meningococcus $\mathrm{C}$ remains in circulation in Cantabria, within the population that was not targeted by the campaign.

Key words: Meningococcus $\mathrm{C}$. Polysaccharide $\mathrm{A}+\mathrm{C}$ meningococcic vaccine. Serum. Antibodics. Immunc Responsc. 


\section{INTRODUCCIÓN}

A principios de 1997 la Consejería de Sanidad detectó en Cantabria un brote epidémico de enfermedad meningocócica. La tasa de incidencia el año anterior había sido de $10.8 / 100.000$, y el porcentaje del serogrupo $\mathrm{C}$ del $53.8 \%$. En las 8 primeras semanas de 1997 se produjo un incremento de 190\% en el total de meningitis meningocócicas y de $260 \%$ en las del serogrupo $\mathrm{C}$ respecto al mismo periodo del año anterior, representando el serogrupo $\mathrm{C}$ el $62 \%$ de los aislamientos. La tasa primaria de ataque por el serogrupo $C$, en el grupo de riesgo de 18 meses a 19 años, superó a principios de febrero la cifra de 10/100.000, llegando en la semana 7 a 14/100.000. Además los casos clínicos revistieron mayor gravedad, con una letalidad del $11.11 \%$ para el serogrupo C. Por otra parte, se detectó la difusión de la misma cepa epidémica que estaba circulando ese año en España (la C: 2b: P1. 2, 5) en los casos en que se serotipo.

Ante esta situación, se realizó una campaña de vacunación del grupo de riesgo que entre el 24 de febrero y el 12 de marzo alcanzó a 100.732 niños, es decir, el 93,45\% de la población diana. En los meses siguientes se mantuvo abierta la vacunación para quienes no se habían vacunado durante la campaña y para los lactantes que fueran cumpliendo 18 meses (este criterio estuvo motivado porque en Cantabria la endemia meningocócica tiene poco carácter estacional, produciéndose tantos casos en primavera-verano como en otoño-invierno). Hasta el 31-12-97 se mantuvo una cobertura vacunal del 95,17\% sólo en el sector público, teniendo en cuenta que después de finalizada la campaña la vacuna estuvo libremente disponible en las farmacias, y muchos niños se vacunaron privadamente.

Después de la campaña de vacunación transcurrió casi un año sin producirse ningún caso de enfermedad meningocócica $\mathrm{C}$ entre los vacunados. En la semana 7 de 1998 se produjo el primero, una niña de 5 años vacunada, con un curso clínico benigno, siendo el único caso ocurrido en los 12 meses siguientes a la vacunación (eficacia vacunal del $95.68 \%$ en todas las edades). La incidencia de enfermedad meningocócica $\mathrm{C}$ en el grupo de riesgo cayó de 21,33/100.000 en los 12 meses anteriores a la campaña a $0,92 / 100.000$ en los 12 siguientes. Esta alta eficacia no pudo ser atribuida a la estacionalidad del meningococo, pues en el resto de la población la incidencia no disminuyó significativamente. Por otra parte, en $4.300 \mathrm{ni}$ ños del grupo de riesgo que quedaron sin vacunar no se produjo ningún caso de meningitis $\mathrm{C}$, pero su escaso número hace que la diferencia no alcance significación estadística, por lo que no puede deducirse que la vacuna induzca inmunidad de rebaño (aspecto éste muy controvertido en la bibliografía $^{1,2,3}$. Por otra parte la letalidad global de la enfermedad, tanto en vacunados como en no vacunados, cayó a cero.

Antes de conocer este buen resultado epidemiológico, y durante el desarrollo del brote epidémico, surgieron dudas sobre la idoneidad de esta vacuna debido a los estudios previos que la atribuían una escasa efectividad (tanto desde el punto de vista clínico como serológico) así como una escasa duración de la protección, sobre todo en los menores de 4-6 años. Estas dudas han hecho que distintos comités de expertos recomienden diferentes pautas de revacunación (entre 1 y 3 años tras la primovacunación en los menores de 4 años), sin que exista uniformidad de criterios. Por ello se decidió realizar un estudio de seroprevalencia en los vacunados, que sirviera de ayuda para decidir la revacunación al acercarnos al límite de eficacia de la vacuna en los niños de menor edad. El objetivo de este trabajo es describir la realización de dicho estudio y sus resultados.

\section{SUJETOS Y MÉTODOS}

Para tener los resultados procesados, las conclusiones elaboradas y toda la maquina- 
ria administrativa dispuesta en febrero-marzo de 1998 (un año tras la primovacunación) en el supuesto que la decisión fuera de revacunar, se planificó la recogida de las muestras en diciembre de 1997, es decir, 10 meses tras la campaña. La recogida de muestras debería realizarse en un tiempo corto (2-4 semanas) para evitar sesgos en cuanto al tiempo transcurrido desde la campaña. Por ello se decidió finalmente recoger los sueros en las 3 primeras semanas de diciembre.

Se dividió a la población de estudio en dos grupos, el primero menor de 4 años y el segundo mayor de esta edad. Los tamaños de muestra de ambos se calcularon con un error alfa $<0.05$ y un error muestral de \pm $5 \%$. El valor de p,q fue de 0,5 para el primer grupo y de $\mathrm{p}=0,9$ para el segundo. Se observará que se buscó un tamaño muestral máximo para el grupo de $<4$ años dada la incertidumbre existente sobre el porcentaje de seroprotección en ellos. De esta manera se obtuvo un tamaño muestral de 373 y 139 respectivamente.

La población objeto del estudio se pretendió conseguir de forma aleatoria entre los niños a quienes se solicitara cualquier analítica en el sistema sanitario público (centros de salud, ambulatorios, consultorios rurales y hospitales), es decir, mediante extracción oportunista de sangre y no realizando una extracción específica, de manera que la colaboración paterna fuera más fácil de conseguir. No obstante, por este sistema el número de niños menores de 4 años sería claramente insuficicnte, debido al escaso número de analíticas que se solicitan en este grupo de edad. Por ello se decidió contar, además, con una muestra recogida específicamente para este estudio, entre los niños escolarizados en las Guarderías dependientes de la Dirección General de Bienestar Social, siendo la mayoría de ellos menores de 4 años. Así pues, la población de estudio obtenida de extracciones oportunistas fue seleccionada al azar, y la obtenida de las guarderías consistió en to- dos los niños vacunados asistentes a las mismas (las 5 guarderías participantes recogían niños procedentes tanto de municipios con casos de meningitis $\mathrm{C}$ como de municipios sin casos). Se consiguieron analizar los sueros de 283 niños entre 1,5 y 6 años, de 76 niños entre 6 y 12 años y de 48 niños entre 12 y 19 años, siendo el $53.2 \%$ mujeres y el $46.7 \%$ varones. El $46 \%$ procedía de extracciones oportunistas y el $54 \%$ de guarderías.

Un mes antes de la recogida de las muestras se efectuaron reuniones informativas con los profesionales implicados (Directores Médicos, Servicios de Laboratorio y de Urgencias de los Hospitales, Pediatras de Atención Primaria y Hospitalaria, y Directores y personal sanitario de las Guarderías) para cxplicarles los objetivos del estudio y recabar su colaboración. Posteriormente se remitió a los profesionales sanitarios información escrita acerca del estudio y pegatinas impresas para rellenar con los datos imprescindibles para la evaluación de los resultados (filiación, fecha de vacunación, marca y lote, enfermedad o tratamiento excluyente, municipio de procedencia, etc). Estas pegatinas eran cumplimentadas por el profesional sanitario que solicitaba la analítica habitual, quien explicaba a la familia los objetivos del estudio y pedía su autorización. Al proceder, en el laboratorio de destino, a la separación de sueros, se apartaba un volumen de 2 cc y se conservaba congelado a $-70^{\circ} \mathrm{C}$ hasta su envío al Instituto de Salud Carlos III para la determinación de anticuerpos.

En las guarderías de la Dirección General de Bienestar Social, donde la extracción de sangre iba a realizarse específicamente para este estudio y sin la presencia de los padres, se organizaron varias reuniones previas con ellos y con el personal, donde se les explicaron los objetivos y se les pidió autorización escrita. Se consiguió un $99.5 \%$ de autorizaciones ( 1 sola negativa en 223 niños), y las extracciones se realizaron en la segunda semana de diciembre por personal de la Consejería de Sanidad desplazado a cada guardería. En estos niños la extracción propia- 
mente dicha se realizó bajo anestesia local de la flexura del codo con la crema EMLA (Lidocaina al 2,5\%+Prilocaina al 2,5\%) para minimizar las molestias.

De la muestra se excluyeron los niños con alguna patología de base que pudiera modificar la respuesta de anticuerpos, tanto al alza (p. ej. padecimiento reciente de una infección por meningococo C) como a la baja (paludismo, inmunodeficiencia, tratamiento inmunosupresor o con dosis farmacológicas de corticoides, neoplasias linfoides, etc. $)^{4}$.

Las determinaciones analíticas se realizaron en el Laboratorio de Neisserias (Dr. Julio Vázquez) del Centro Nacional de Microbiología de Majadahonda (Instituto de Salud Carlos III), utilizándose la tasa de anticuerpos bactericidas, según la técnica estandarizada por varios laboratorios europeos, canadienses y norteamericanos 5 . Estos anticuerpos guardan mayor relación con la protección clínica que los anticuerpos contra el polisacárido capsular, y se estableció el nivel de «efecto vacunal» en la dilución $\geq 1 / 8$ (este título fue el sugerido por el Instituto de Salud Carlos III para unificar la evaluación de los estudios que se realicen en diferentes Comunidades Autónomas, aunque algunos trabajos de la bibliografía lo sitúan en 1/4).

El análisis estadístico de los resultados se efectuó mediante el paquete informático «Epi Info Versión $6{ }^{6}{ }^{6}$, empleándose técnicas no paramétricas cuando fueron precisas. Las vacunas utilizadas fueron la «Antimeningocócica $\mathrm{A}+\mathrm{C} \gg$ de Laboratorio Pasteur Merieux (Lotes M6419-1 y M1373-1 para el liofilizado y M6450-1 para el disolvente) y «Mencevax» del Laboratorio SmithKline Beecham (Lote N258A11A para el liofilizado, y 96J 23/33 para el disolvente, la presentación de 10 dosis, y lote N264A54A para el liofilizado y $96.119 / 53$ para el disolvente, la presentación de 50 dosis). Ambas vacunas contienen $50 \mu \mathrm{g}$ del polisacárido capsular del meningococo A y $50 \mu \mathrm{g}$ del C por cada dosis.

\section{RESULTADOS}

Se obtuvieron 423 muestras de suero, de las que finalmente resultaron válidas para el estudio 414. Las exclusiones fueron por antecedentes personales del niño en 4 casos ( 2 por meningitis y 2 por tratamiento inmunosupresor o corticoterapia) y 6 por problemas técnicos en el laboratorio (1.19\% de la muestra válida), uno de los cuales era el que estaba recibiendo corticoterapia. La distribución por edades puede verse en la Tabla 1. El número de sueros estudiados en mayores de 4 años (184) fue mayor del previsto. Aunque el número de sueros de menores de 4 años (228) fue menor del previsto, el porcentaje de «seroprotección» encontrado fue $\tan$ bajo, tan alejado del 0.5 inicialmente empleado para el cálculo del tamaño muestral, que consideramos suficiente el tamaño muestral finalmente conseguido.

La mediana del título de anticuerpos bactericidas, así como el porcentaje de niños con título $\geq 1 / 8$, y su distribución estratificada por edades puede verse en la Tabla 1. En la Tabla 2 se presentan los datos agrupados por los segmentos de edad más utilizados en la bibliografía, para facilitar las comparaciones. Es evidente la relación directa de la seropositividad y la mediana del título con la edad del niño al vacunarse, con una llamativa «desprotección» teórica en los vacunados con 18-24 meses, siendo el primer incremento significativo en el porcentaje de «protegidos» en el grupo de vacunados con 4 y 5 años, y consiguiendo un porcentaje de seroprotección superior al $50 \%$ sólo los vacunados con más de 8 años. El porcentaje tan bajo de seroprotección reflejado en el total de la muestra (Tabla 1) debe atribuirse a que el estudio estaba diseñado principalmente para los menores de 4 años (en los que deseábamos conocer más datos de cara a su revacunación) y por lo tanto ellos constituyen el grueso de la muestra, concretamente el $55 \%$ del total. 
Tabla 1

Título de anticuerpos bactericidas 10 meses tras la vacunación antimeningocócica con polisacárido capsular A+C. distribución por edades

\begin{tabular}{|c|c|c|c|c|c|c|}
\hline Edad al vacunarse & $N .^{o}$ niños & $\begin{array}{c}\text { Título } \\
\text { (mediana) }\end{array}$ & $\begin{array}{c}\text { Comparación } \\
\text { de medianas } \\
p^{*}\end{array}$ & $\begin{array}{c}\text { Título } \geq 1 / 8 \\
n .^{\circ}(\%)\end{array}$ & $\begin{array}{c}\text { Comparación } \\
\text { de } \\
\text { porcentajes } \\
p^{*}\end{array}$ & $\begin{array}{c}\text { I.C. al } 95 \% \\
\text { del porcentaje } \geq \\
1 / 8\end{array}$ \\
\hline $18-24$ meses (1,5-2 años) & 57 & $<1 / 8$ & & $0(0,0 \%)$ & & $0,0-7,8 \%$ \\
\hline 25-36 meses ( 2 años) & 98 & $<1 / 8$ & $<0,05$ & $8(8,2 \%)$ & NS & $3,8-15,9 \%$ \\
\hline 37-48 meses ( 3 años) & 73 & $<1 / 8$ & $<0,05$ & $1(1,4 \%)$ & NS & $0,1-8,4 \%$ \\
\hline $49-72$ meses ( 4 y 5 años) & 60 & $<1 / 8$ & $<0,05$ & $11(18,3 \%)$ & $<0,05$ & $9,9-30,8 \%$ \\
\hline 73-96 meses (6 y 7 años) & 24 & $<1 / 8$ & NS & $9(37.5 \%)$ & NS & $19,5-59,2 \%$ \\
\hline $97-120$ meses ( 8 y 9 años) & 22 & $1 / 35,5^{* *}$ & NS & $11(50,0 \%)$ & NS & $28,8-71,2 \%$ \\
\hline $121-144$ meses ( 10 y 11 años) & 30 & $1 / 96$ & NS & $19(63,3 \%)$ & NS & $43,9-79,5 \%$ \\
\hline $145-168$ meses ( 12 y 13 años) & 21 & $1 / 128$ & NS & $17(81,0 \%)$ & NS & $57,4-93,7 \%$ \\
\hline$>168$ meses (14 a 19 años) & 27 & $1 / 256$ & NS & $22(81,5 \%)$ & NS & $61,2-92,9 \%$ \\
\hline TOTAL & $414^{* * *}$ & $<1 / 8$ & & $98(23,7 \%)^{* * * *}$ & & $19,7-28,1 \%$ \\
\hline
\end{tabular}

(*) Significación estadística con relación al grupo de edad anterior.

$\left.{ }^{(* *}\right)$ Número par de determinaciones.

(***) De 2 niños no consta la edad.

(****) Porcentaje total no valorable al estar en la nuestra excesivamente representados $\operatorname{los}<4$ años

Tabla 2

Título de anticuerpos bactericidas 10 meses tras la vacunación antimeningocócica con polisacárido capsular $\mathbf{A}+\mathrm{C}$. Distribución por edades agrupadas.

\begin{tabular}{|lccccc|}
\hline Segmentos de edad & N. niños & $\begin{array}{c}\text { Título } \\
\text { (mediana) }\end{array}$ & $\begin{array}{c}\text { Título } \geq 1 / 8 \\
N^{\circ} \text { niños }\end{array}$ & $\begin{array}{c}\text { I.C. al 95\% del } \\
\text { porcentaje } \geq 1 / 8\end{array}$ \\
\hline $18-48$ meses $(>1.5$ y $<4$ años) & 228 & $<1 / 8$ & 9 & $4,0 \%$ & $2,0-7.6 \%$ \\
$18-72$ meses $(>1.5$ y $<6$ años) & 288 & $<1 / 8$ & 20 & $6,9 \%$ & $4,4-10,7 \%$ \\
$73-144$ meses $(>=6$ y $<12$ años) & 76 & $1 / 24 *$ & 39 & $51,3 \%$ & $39,7-62,8 \%$ \\
$>144$ meses $(>=12$ y $<20$ años) & 48 & $1 / 192 *$ & 39 & $81,2 \%$ & $66,9-90,6 \%$ \\
\hline
\end{tabular}

(*) Número par de determinaciones.

Debido a que la definición de «efecto vacunal» se cifró en la dilución $1 / 8$ de forma artificial, y a que otros trabajos la cifran en $1 / 4$ 7.8 .9 , en 287 sueros de los 316 con resultado $<1 / 8$ se repitió el ensayo bactericida con la dilución $1 / 4$ (es decir, el $90.8 \%$ de los $<1 / 8$ fueron titulados además a 1/4). De los 287 titulados a 1/4, 286 (el 99.6\%) dieron también negativo a esta dilución, por lo que el resultado final no varía si situamos el punto de corte en la dilución $1 / 4$ en vez de en 1/8.

Se comparó la mediana del título de anticuerpos y el porcentaje de niños con título $\geq 1 / 8$ según procedieran de municipios donde había habido casos de enfermedad meningo- cócica $\mathrm{C}$ en los años 96 y 97, o de municipios libres de casos. Se habían declarado casos en 16 de los 102 municipios de Cantabria. No se apreciaron diferencias estadísticamente significativas entre ambos grupos (tabla 3 ).

Finalmente se comparó la respuesta serológica a cada tipo de vacuna utilizada, no encontrándose diferencias estadísticamente significativas entre ambas.

\section{DISCUSIÓN}

La evolución de la enfermedad en Cantabria, resumida en la Introducción, muestra la 
Tabla 3

Título de anticuerpos bactericidas 10 meses tras la vacunación antimeningocócica con polisacárido capsular $\mathrm{A}+\mathrm{C}$. Comparación por municipios con y sin casos

\begin{tabular}{|c|c|c|c|c|c|c|c|c|}
\hline \multirow[b]{2}{*}{ Edad al vacunarse } & \multicolumn{2}{|c|}{$\begin{array}{c}N^{o}{ }^{o} \text { niños por } \\
\text { munic. }\end{array}$} & \multicolumn{3}{|c|}{ Mediana del titulo } & \multicolumn{3}{|c|}{$\%$ con título $\geq 1 / 8$} \\
\hline & $\begin{array}{l}\text { Con } \\
\text { casos }\end{array}$ & $\begin{array}{l}\text { Sin } \\
\text { casos }\end{array}$ & $\begin{array}{c}\text { Munic. } \\
\text { con } \\
\text { casos }\end{array}$ & $\begin{array}{c}\text { Munic. } \\
\text { sin } \\
\text { casos }\end{array}$ & $p$ & $\begin{array}{c}\text { Munic. } \\
\text { con } \\
\text { casos }\end{array}$ & $\begin{array}{c}\text { Munic. } \\
\text { sin } \\
\text { casos }\end{array}$ & $p$ \\
\hline $18-24$ meses ( $1.5-2$ años) & 43 & 14 & $<1 / 8$ & $<1 / 8$ & NS & $0,0 \%$ & $0,0 \%$ & NS \\
\hline 2536 meses ( 2 años) & 82 & 16 & $<1 / 8$ & $<1 / 8$ & NS & $8,5 \%$ & $6,3 \%$ & NS \\
\hline 37-48 meses ( 3 años) & 61 & 12 & $<1 / 8$ & $<1 / 8$ & NS & $1,6 \%$ & $0,0 \%$ & NS \\
\hline $49-72$ meses ( 4 y 5 años) & 56 & 4 & $<1 / 8$ & $<1 / 8$ & NS & $17,9 \%$ & $25,0 \%$ & NS \\
\hline 73-96 meses ( 6 y 7 años) & 22 & 2 & $<1 / 8$ & $1 / 11,5^{*}$ & NS & $36,4 \%$ & $50,0 \%$ & NS \\
\hline $97-120$ meses ( 8 y 9 años) & 14 & 8 & $1 / 35,5^{*}$ & $1 / 67,5^{*}$ & NS & $50,0 \%$ & $50,0 \%$ & NS \\
\hline $121-144$ meses ( 10 y 11 años) & 24 & 6 & $1 / 64$ & $1 / 192^{*}$ & NS & $62,5 \%$ & $66,7 \%$ & NS \\
\hline $145-168$ meses (12 y 13 años) & 11 & 10 & $1 / 64$ & $1 / 384 *$ & NS & $72,7 \%$ & $90,0 \%$ & NS \\
\hline$>168$ meses ( 14 a 19 años) & 22 & 5 & $1 / 256$ & $1 / 128$ & NS & $86,4 \%$ & $60,0 \%$ & NS \\
\hline Total & 335 & 79 & $<1 / 8$ & $<\mathrm{l} / 8$ & NS & $22,4 \%$ & $29,1 \%$ & NS \\
\hline
\end{tabular}

(*) Número par de determinaciones.

eficacia clínico-epidemiológica de la vacuna en el control del brote, que fue incluso superior a lo publicado. En efecto, se han descrito los siguientes porcentajes de protección clínica por edades: en los niños mayores y adultos $85-100 \%$, en los menores de 5 años $70 \%$, entre los 18 -24 meses y los 3 años $55-75 \%$, y poca eficacia en los menores de 18-24 meses ${ }^{1-3,7,9}$. En Cantabria, la eficacia vacunal fue del $95.68 \%$ en la totalidad del grupo de riesgo (18 meses a 19 años) en el año siguiente a la vacunación, atribuyendo este buen resultado a haber realizado la campaña en el pico ascendente de la epidemia y a su rapidez ( 2 semanas), lo que sin duda bloqueó la transmisión del germen en el grupo de riesgo y potenció la efectividad de la vacuna en cada caso individual ${ }^{1-3}$.

No obstante, en España las últimas ondas epidémicas han tenido una duración de 2-4 años (la que tuvo su pico en 1979 duró 7 años) $)^{2}$. Ello nos hizo temer que al acercarnos al límite de eficacia de la vacuna en los más pequeños (entre 1 y 3 años, según los expertos) volvieran a declararse casos, sobre todo teniendo en cuenta que este límite se alcanzaría en Cantabria en febrero-marzo de 1998, es decir, en época clásicamente considerada de riesgo, y que el meningococo C había seguido circulando en la población, lo que se comprobó por no haber disminuido significativamente la incidencia en los no vacunados. Ello nos hizo organizar el presente estudio serológico que, con las limitaciones que se comentarán a continuación, esperábamos que nos ayudara a tomar una decisión acerca de la revacunación de los más pequeñitos, sobre todo los menores de 4 años.

Los estudios de seroprotección tienen las siguientes limitaciones: 1) $\mathrm{Al}$ ser una vacuna de uso en situaciones epidémicas, se aplica a muchos que ya son portadores del meningococo, y que por tanto tienen inmunidad natural; 2) No está determinado exactamente el nivel protector de los anticuerpos (habitualmente se miden los anticuerpos contra el polisacárido capsular, sugiriéndose un nivel protector de 1-2 $\mu \mathrm{g} / \mathrm{ml}$, y los anticuerpos «bactericidas», más relacionados con la protección clínica, sugiriéndose un nivel protector de 1/4 a 1/8),7,10-12; 3) En varios trabajos se han usado dosis diferentes de vacuna, des- 
de 5 hasta $200 \mu \mathrm{g}$, no siendo todos los resultados comparables; y 4) No está clara la relación entre anticuerpos y protección clínica, pues en ausencia de anticuerpos pueden existir otros mecanismos inmunológicos no bien conocidos que protejan al niño, como evidentemente está ocurriendo en Cantabria al comparar la escasa «protección» serológica con el buen efecto clínicoepidemiológico.

Con estas limitaciones, podemos separar 4 grupos de edad con una respuesta de anticuerpos diferenciada, si bien esta separación debe ser tomada con cautela ya que algunos estudios no permiten una diferenciación por edades tan precisa:

1) Menores de 6 meses: en ellos la vacuna es ineficaz, y puede ser perjudicial por inducir «fenómeno de supresión» (la revacunación posterior da lugar a tasas de protección menores que si se hubiera aplicado la primovacunación a la edad de la $2 .^{\text {a do- }}$ sis) $)^{8,13,14}$.

2) De 6 a 18 meses: en ellos cabe esperar que el $65 \%$ desarrolle anticuerpos contra el polisacárido $\mathrm{C}$ y $30-75 \%$ anticuerpos bactericidas ${ }^{8.10 .15}$. Estos decaen rápidamente en los 3 primeros meses, y el porcentaje que mantiene actividad bactericida al año es bajísimo $(9 \%)^{9,10}$ por lo que deben ser revacunados pronto. Esta revacunación precoz no produce más reacciones adversas y no induce fenómeno de supresión ${ }^{8.12,13.16}$, y consigue niveles de anticuerpos similares, o sólo ligeramente superiores, a los de una primovacunación (es decir, tiene un efecto «booster» débil pero desde luego resulta inmunógena $)^{4.8 .11 .12}$. Con estos datos de eficacia relativa, pero ausencia de efectos perjudiciales, algunos autores recomiendan vacunar en situación epidémica desde los 6 meses (y así se ha hecho en Canadá, Australia, Brasil, Finlandia, EEUU, etc.) revacunando entre 3 y 12 meses después si persiste el riesgo ${ }^{1.89} \cdot 10,12,16$. No obstante, esta recomendación y sus maticcs no suele recogerse en la bibliografía.
3) De 18 meses a 4 años: en ellos la vacuna induce casi la misma seroprotección a corto plazo que en los más mayores, pero la duración es muy corta: en el grupo de 2-6 años sólo el $20 \%$ mantienen actividad bactericida al año de la vacunación ${ }^{7}$, aunque otros autores no dan resultados tan pesimistas. Esta corta duración hace recomendar la revacunación de este grupo según distintas pautas. La AAP, con un enfoque dirigido a la práctica clínica individual, recomienda «considerar» la revacunación del grupo de $<4$ años un año después de la primovacunación ${ }^{17}$. La Agencia de Evaluación de las Tecnologías Sanitarias recomienda considerar la revacunación del grupo de 2 a 6 años a los 1-2 años de la primovacunación ${ }^{9}$. Y todos los demás autores y Comités que han hecho recomendaciones (como el ACIP, que orienta más desde el punto de vista de la Salud Pública, o las publicaciones canadienses) $)^{1,10,15}$, recomiendan revacunar al grupo de $<4$ años a los 2-3 años de la primovacunación. En todos los casos, por supuesto, si persiste el riesgo epidémico.

4) Mayores de 4 años y adultos: en este grupo la duración de los anticuerpos bactericidas va aumentando con la edad, desde un $40-50 \%$ de persistencia al año de la primovacunación en los niños de 6 años, un 54\% al año de la primovacunación en los chicos de 13-19 años ${ }^{7}$, hasta un 70-90\% de persistencia a los 5-10 años en adultos. Por ello se recomienda revacunar pasados 2-5 años a los más pequeños de este grupo, hasta pasados 5-10 años los adultos, siempre que persista el riesgo epidémico $0^{9,15}$. No obstante, antes de este plazo habrá nuevas vacunas conjugadas con una proteína transportadora (de manera similar a lo ocurrido con la vacuna del $\mathrm{Hib}$ ), más eficaces que las actuales en todos los grupos de edad, incluyendo los lactantes, por lo que estas recomendaciones se actualizarán con toda seguridad ${ }^{4.18}$.

En nuestra experiencia, la actividad bactericida a los 10 meses de la vacunación es de $0 \%$ de títulos $\geq 1 / 8$ en los vacunados con 18-24 meses, de $4 \%$ en los vacunados con 
1.5 a 4 años, de $6,9 \%$ en los vacunados con 1.5 a 6 años, de $51,3 \%$ en los vacunados con 6 a 12 años y de $81,2 \%$ en los vacunados con 12 a 19 años (datos agrupados en Tabla 2), lo que coincide bastante con lo publicado, salvo por una menor seroprevalencia en los menores de 6 años. Además el resultado no variaría si el punto de corte de la positividad se situase en $1 / 4$ en lugar de en 1/8. No obstante, insistimos en la disociación entre la «seroprotección» (medida por los anticuerpos bactericidas) y la protección clínica (medida por la caída en la tasa de ataque de la enfermedad), por lo que sin duda existen otros mecanismos de protección no conocidos todavía.

Sorprende a primera vista que los niños procedentes de municipios con casos de enfermedad meningocócica $\mathrm{C}$ en los años 1996 y 1997 no presentaran mayor tasa de seropositividad tras la vacunación. Podría esperarse una mayor seropositividad si en esos municipios hubiera más portadores, pues se ha comprobado que el estado de portador induce anticuerpos protectores en más del $90 \%$ de los casos contra la cepa portada (y en más del $80 \%$ contra otros meningococos por inmunización cruzada ${ }^{4}$ ), y que la respuesta a la vacuna cstá potenciada por la existencia previa de anticuerpos obtenidos por exposición a la infección natu$\mathrm{ral}^{11,12,14}$. Pero en la práctica esta ausencia de relación con la procedencia de una zona endémica coincide con la experiencia de Canadá 7 y tal vez debamos atribuirlo a que en las situaciones epidémicas o hiperendémicas el reservorio de la enfermedad se encuentra en portadores adultos, siendo excepcional el estado de portador en la edad pediátrica, que suele ser la analizada en los estudios de seroprotección $(0,58 \%$ de portadores en Canadá en el grupo de 6 meses a 19 años, siendo el $80 \%$ de los colonizados mayores de 15 años) ${ }^{10}$. Esto ha sido comprobado en el mayor estudio de portadores realizado hasta la fecha en el mundo, llevado a cabo precisamente en Galicia a raíz del brote epidémico de 1996-97, en el cual se tomaron frotis nasofaríngeos a 9.796 niños y adolescentes de 2 a 19 años, comparándose posteriormente los resultados según la procedencia de un área con alta incidencia de enfermedad meningocócica o una de baja incidencia ${ }^{19}$. El resultado final es que sólo el $8,76 \%$ de los niños de 2-19 años eran portadores de N. Meningitidis, y sólo el $1.33 \%$ del serogrupo $\mathrm{C}$, en el área de alta incidencia, porcentajes que en el área de baja incidencia cran del 8.03 y del $0.89 \%$ respectivamente, siendo en ambas áreas los porcentajes más pequeños cuanto menor era la edad del niño. Todos estos datos nos hacen suponer que la tasa de seroprotección encontrada en Cantabria se deba prioritariamente a la vacunación, y que el posible efecto de la inmunidad natural preexistente sea despreciable, aunque esta afirmación la hagamos con todas las cautelas, al no disponer de estudios de portadores en nuestra Comunidad ni haber realizado un estudio serológico prevacunal debido a la urgencia con que se debió realizar la campaña de vacunación.

En conclusión, se han encontrado tasas muy bajas de anticuerpos bactericidas a los 10 meses de la vacunación en los menores de 4-6 años, algo inferiores a las publicadas, siendo en los mayores de 6 años similares a las descritas en la bibliografía. A pesar de ello, el efecto clínico-epidemiológico de la vacuna sigue siendo excelente en todos los grupos de edad un año después de la vacunación, por lo que probablemente existen otros factores inmunológicos desconocidos, distintos de los anticuerpos, que protegen de la enfermedad. Nuestra opinión, que coincide con la de casi todos los expertos, es que la decisión de revacunar debe tomarse teniendo en cuenta, principalmente, la evolución clínico-epidemiológica. Los estudios serológicos deberían servir únicamente como una ayuda si lo anterior no fuera concluyente, o para delimitar los subgrupos susceptibles de revacunación y no tener que revacunar a la totalidad del grupo de riesgo (18 meses a 19 años). Pero precisamente por el papel crucial de la epidemiología, y por la ambiguiedad con que en la bibliografía se habla de la revacunación «si persistiera el 
riesgo epidémico» sin definir este concepto, nos parece urgente llegar a un consenso entre todas las Comunidades Autónomas en cuanto a los criterios epidemiológicos que sustentarían la decisión de revacunación. Este consenso racionalizaría la decisión en términos científicos, ayudaría a que la asignación de recursos económicos para la campaña de revacunación fuera coherente, y a que España no pase a la historia por haber dilapidado unos stoks de vacuna que a nivel mundial son escasos y mucho más necesarios en otros países (en algunos países africanos las epidemias superan los 15 casos/100.000 habitantes/semana!).

\section{AGRADECIMIENTOS}

\section{Al Dr Manuel Ortega Mendi, Director} General de Sanidad y Consumo de Cantabria, al Dr Germán Romero; a la Dra María Mambrilla; a todos los profesionales sanitarios (médicos y ATS) de Cantabria; al personal del Laboratorio de Neisserias del Instituto de Salud Carlos III; y finalmente a los padres de todos los niños que han participado en este estudio, por confiar en la Sanidad Pública para vacunar a sus hijos cuando así se recomendó, y por su solidaridad al autorizar la realización de la serología, lo que nos permitirá hacer recomendaciones sanitarias para toda la Comunidad Autónoma.

\section{BIBLIOGRAFÍA}

1. Gonzalez Arraez JI, Saiz Sanchez C, Cortina Birlanga S y Cortina Greus P. Vacunas frente al meningococo serogrupo C. Med Integral 1997; 30: 222-226.

2. Cortina S, Talamante S, Corella D y Giménez FJ. Situación actual de las vacunas antimeningocócicas. Med Integral 1997; 29: 84-87.

3. De Wals P, Dionne M, Douville-Fradet M, Boulianne N, Drapeau J and De Serres G. Impact of a mass immunization campaign against serogroup $\mathrm{C}$ meningococcus in the province of Quebec, $\mathrm{Ca}$ nada. WHO Bulletin 1996; 74: 407-411.
4. Riedo FX, Plicaytis BD and Broome CV. Epidemiology and prevention of meningococcal disease. Pediatr Infect Dis J 1995; 14: 643-57.

5. Maslanka SE, Gheesling LL, Libutti DE, Donaldson K, Harakeh HS, Dykes JK et al. Standardization and Multilaboratory comparison of Neisseria Meningitidis serogroup A and C serum bactericidal assays. Clin Diagn Labor Inmunol 1997; 4: 156-167.

6. Dean AC, Dean JA, Coulombier D et al. Epi Info Version 6: a word processing, database and statistics program for epidemiology on microcomputers. Georgia: Centers for Disease Control and Prevention; 1994.

7. Mitchell LA, Ochnio JJ, Glover C, Lee AY, Ho M and Bell A. Analysis of meningococcal serogroup $\mathrm{C}$-specific antibody levels in British Columbia children and adolescents. J Infect Dis 1996; 173: 1009-13.

8. Peltola H, Safari A, Kayhty H, Karanko V, y André FE. Valoración de dos vacunas meningocócicas tetravalentes (ACYW135) en lactantes y niños pequeños. Estudio clínico comparando el efecto inmunógeno de los polisacáridos 0 -acetil negativo y 0 -acetil positivo del grupo C. Pediatrics (ed.esp.) 1985; 20: 54-58.

9. Ministerio de Sanidad Y Consumo, Instituto de Salud Carlos III, Agencia de Evaluación de las T'ecnologías Sanitarias (AETS). Eficacia de la vacuna meningocócica de polisacárido capsular del grupo C. Madrid: AETS - Instituto de Salud Carlos III: 1997.

10. King WJ, Macdonald NE, Wells G, Huang J, Allen $\mathrm{U}$, Chan $\mathrm{F}$ et al. Total and functional antibody response to a quadrivalent meningococcal polysaccharide vaccine among children. J Pediatr 1996; 128: 196-202.

11. Lepow ML, Beeler J, Randolph M, Samuelson IS and Hankins WA. Reactogenicity and immunogenicity of a quadrivalent combined meningococcal polysaccharide vaccine in children. $J$ Infect Dis 1986; 154: 1033-1036.

12. Gold R, Lepow ML, Goldschneider I. Draper TF, and Gotschlich EC. Kinetics of antibody production to group $\mathrm{A}$ and group $\mathrm{C}$ meningococcal polysaccharide vaccines administered during the first six years of life: prospects for routine inmunization of infants and children. J Infect Dis 1979; 140 : 690-97.

13. Lepow ML, Goldschneider I, Gold R. Randolph $\mathrm{M}$ and Gotschlich EC. Persistence of antibody following immunization of children with groups $\mathrm{A}$ and $\mathrm{C}$ meningococcal polysaccharide vaccines. Pediatrics 1977; 60: 673-680. 
14. Gold R, Lepow ML, Goldschneider I, Draper TL and Gotschlich EC. Clinical evaluation of group $\mathrm{A}$ and group $\mathrm{C}$ meningococcal polysaccharide vaccines in infants. J Clin Invest 1975; 56: 1536-1547.

15. Centers For Disease Control And Prevention. Control and prevention of meningococcal disease and Control and prevention of serogroup $\mathrm{C}$ meningococcal disease: evaluation and management of suspected outbreaks: recommendations of the Advisory Committee on Inmunization Practices (ACIP). MMWR 1997; 46 (No. RR-5): 1-21.

16. Pearce MC, Sheridan JW, Jones DM, Lawrence GW, Murphy DM, Masutti B et al. Control of group $\mathrm{C}$ meningococcal disease in australian aboriginal children by mass rifampicin chemoprofilaxis and vaccination. The Lancet 1995; 346: 20-23.
17. American Academy of Pediatrics. Meningococcal disease prevention and control strategies for practice-based physicians. Pediatrics 1996; 97 : 404-411.

18. Leach A, Twumasi PA, Kumach S, Banya WS, Jaffar S, Forrest BD et al. Induction of immunologic memory in Gambian children by vaccinationin infancy with a group A plus group $\mathrm{C}$ meningococcal polysaccharide-protein conjugate vaccine. J Infect Dis 1997; 175: 200-204.

19. Direccion Xeral de Saude Publica, Xunta de Galicia. Portadores de N.Meningitidis e incidencia de enfermidade meningocócica. Boletín Epidemiolóxico de Galicia 1997; Vol X, n. ${ }^{\circ} 3$. 